\title{
Toward a combined SAGE II-HALOE aerosol climatology: an evaluation of HALOE version 19 stratospheric aerosol extinction coefficient observations
}

\author{
L. W. Thomason \\ NASA Langley Research Center, Mail Stop 475, Hampton, VA 23681, USA \\ Correspondence to: L. W. Thomason (1.w.thomason@ nasa.gov)
}

Received: 15 March 2012 - Published in Atmos. Chem. Phys. Discuss.: 5 June 2012

Revised: 13 August 2012 - Accepted: 16 August 2012 - Published: 12 September 2012

\begin{abstract}
Herein, the Halogen Occultation Experiment (HALOE) aerosol extinction coefficient data is evaluated in the low aerosol loading period after 1996 as the first necessary step in a process that will eventually allow the production of a combined HALOE/SAGE II (Stratospheric Aerosol and Gas Experiment) aerosol climatology of derived aerosol products including surface area density. Based on these analyses, it is demonstrated that HALOE's $3.46 \mu \mathrm{m}$ is of good quality above $19 \mathrm{~km}$ and suitable for scientific applications above that altitude. However, it is increasingly suspect at lower altitudes and should not be used below $17 \mathrm{~km}$ under any circumstances after 1996 . The $3.40 \mu \mathrm{m}$ is biased by about $10 \%$ throughout the lower stratosphere due to the failure to clear $\mathrm{NO}_{2}$ but otherwise appears to be a high quality product down to $15 \mathrm{~km}$. The 2.45 and $5.26 \mu \mathrm{m}$ aerosol extinction coefficient measurements are clearly biased and should not be used for scientific applications after the most intense parts of the Pinatubo period. Many of the issues in the aerosol data appear to be related to either the failure to clear some interfering gas species or doing so poorly. For instance, it is clear that the $3.40 \mu \mathrm{m}$ aerosol extinction coefficient measurements can be improved through the inclusion of an $\mathrm{NO}_{2}$ correction and could, in fact, end up as the highest quality overall HALOE aerosol extinction coefficient measurement. It also appears that the 2.45 and $5.26 \mu \mathrm{m}$ channels may be improved by updating the Upper Atmosphere Pilot Database which is used as a resource for the removal of gas species otherwise not available from direct HALOE measurements. Finally, a simple model to demonstrate the promise of mixed visible/infrared aerosol extinction coefficient ensembles for the retrieval of bulk aerosol properties demonstrates that a
\end{abstract}

combined HALOE/SAGE II aerosol climatology is feasible and may represent a substantial improvement over independently derived data sets.

\section{Introduction}

In the stratosphere, where aerosol composition is predominately mixtures of $\mathrm{H}_{2} \mathrm{SO}_{4}$ and $\mathrm{H}_{2} \mathrm{O}$, aerosol extinction at Halogen Occultation Experiment (HALOE) wavelengths is dominated by absorption. Variation with wavelength is mostly driven by changes in the imaginary index of refraction that are themselves modulated by temperature and relative humidity. The extinction measurements generally exhibit a second order dependence on aerosol size. As such, infrared aerosol extinction coefficient measurements are nearly linearly related to total aerosol volume but provide limited information on aerosol size distribution. This stands in contrast to similar measurements in the visible and near infrared where absorption by sulfate aerosol is effectively zero and extinction is dominated by the positive wing of the aerosol size distribution with limited dependence on the smallest aerosol present. This can be seen in Fig. 1 which shows Mie extinction kernels scaled to per unit volume of aerosol and for measurement wavelength for $75 \% \mathrm{H}_{2} \mathrm{SO}_{4}$ $25 \% \mathrm{H}_{2} \mathrm{O}$ aerosol at $220 \mathrm{~K}$ at HALOE and some SAGE II/III (the Stratospheric Aerosol and Gas Experiment) measurement wavelengths (a unitless quantity). A substantial history of visible/near infrared extinction coefficient measurements has been produced by the SAGE-series of instruments (listed in Table 1). The information content of infrared 


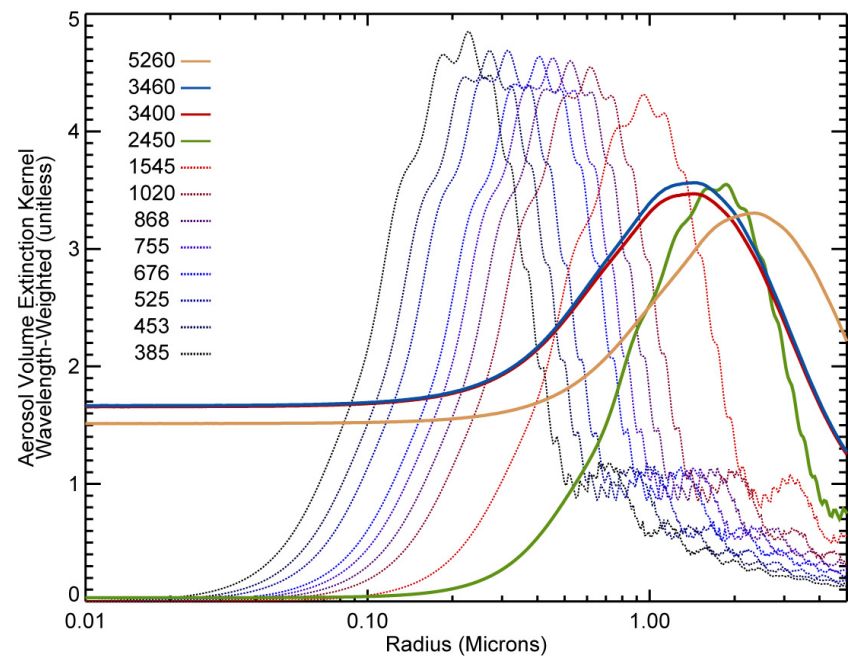

Fig. 1. This figure shows the Mie aerosol extinction coefficient kernels (per unit volume of aerosol and wavelength-weighted, a unitless quantity) weighted by wavelength for a $75 \% \mathrm{H}_{2} \mathrm{SO}_{4} / 25 \% \mathrm{H}_{2} \mathrm{O}$ aerosol at stratospheric temperatures for SAGE II/III and HALOE measurement wavelengths. Dotted lines are kernels for SAGE II/III wavelengths and solid lines are for HALOE wavelengths.

Table 1. The Stratospheric Aerosol and Gas Experiment (SAGE) series of instruments including the Stratospheric Aerosol Measurement (SAM II).

\begin{tabular}{lll}
\hline Instrument & $\begin{array}{l}\text { Dates of } \\
\text { Operation }\end{array}$ & $\begin{array}{l}\text { Aerosol Extinction Coefficient } \\
\text { Measurement Wavelengths }\end{array}$ \\
\hline SAM II & $1978-1993$ & $1000 \mathrm{~nm}$ \\
\hline SAGE & $1979-1981$ & $450,1000 \mathrm{~nm}$ \\
\hline SAGE II & $1984-2005$ & $386,452,525,1020 \mathrm{~nm}$ \\
\hline SAGE III & $2002-2006$ & $\begin{array}{l}386,448,521,602,676,755, \\
868,1019,1545 \mathrm{~nm}\end{array}$ \\
\hline
\end{tabular}

measurements (from HALOE) and visible/near infrared measurements (from SAGE II/III) is sufficiently different that the combination of these measurements may substantially reduce the uncertainty of indirectly derived aerosol products such as aerosol surface area density (SAD) (e.g., Thomason et al., 2008).

HALOE is a gas-filter correlation radiometer that uses solar occultation to measure vertical profiles of a number of important trace gas species and multiwavelength aerosol extinction coefficient from the upper troposphere as high as the thermosphere. It was deployed as a part of the Upper Atmosphere Research Satellite from the space shuttle Discovery on 15 September 1991 and operated through November 2005 when the mission was terminated. HALOE measurement species include $\mathrm{O}_{3}, \mathrm{H}_{2} \mathrm{O}, \mathrm{CH}_{4}, \mathrm{NO}, \mathrm{NO}_{2}, \mathrm{HCl}, \mathrm{HF}$ and temperature (via $\mathrm{CO}_{2}$ absorption). Data from this mis-
Table 2. HALOE aerosol measurement locations with primary gas species and other absorbers, ${ }^{a}$ indicates that the species is cleared using HALOE derived products (clearing is inferred by the inclusion of their uncertainties in the aerosol uncertainty as noted in Hervig et al., 1995). The symbol ${ }^{b}$ indicates that this species is removed using climatological values (M. Hervig, personal communication, 2012). The symbol ${ }^{\mathrm{c}}$ denotes that, while $\mathrm{NO}_{2}$ is measured by HALOE, it is not removed from this aerosol product (E. Remsberg, personal communication, 2012).

\begin{tabular}{lll}
\hline $\begin{array}{l}\text { Wavelength } \\
(\mu \mathrm{m})\end{array}$ & $\begin{array}{l}\text { Primary } \\
\text { Gas Species }\end{array}$ & Other Absorbers \\
\hline 2.45 & $\mathrm{HF}^{\mathrm{a}}$ & $\mathrm{H}_{2} \mathrm{O}^{\mathrm{a}}, \mathrm{CH}_{4}{ }^{\mathrm{a}}, \mathrm{CO}_{2}{ }^{\mathrm{b}}, \mathrm{O}_{3}, \mathrm{~N}_{2} \mathrm{O}$ \\
3.40 & $\mathrm{HCl}^{\mathrm{a}}$ & $\mathrm{CH}_{4}^{\mathrm{a}}, \mathrm{O}_{3}{ }^{\mathrm{a}}, \mathrm{H}_{2} \mathrm{O}^{\mathrm{a}}, \mathrm{NO}_{2}{ }^{\mathrm{c}}$ \\
3.46 & $\mathrm{CH}_{4}{ }^{\mathrm{a}}$ & $\mathrm{NO}_{2}{ }^{\mathrm{a}}, \mathrm{H}_{2} \mathrm{O}^{\mathrm{a}}, \mathrm{HCl}^{\mathrm{a}}$ \\
\hline 5.26 & $\mathrm{NO}^{\mathrm{a}}$ & $\mathrm{N}_{2} \mathrm{O}, \mathrm{CO}_{2}{ }^{\mathrm{b}}, \mathrm{H}_{2} \mathrm{O}^{\mathrm{a}}, \mathrm{O}_{3}{ }^{\mathrm{a}}$ \\
\hline
\end{tabular}

sion were instrumental in the discovery of the water vapor tape recorder (Mote et al., 1996) and trends in $\mathrm{HCl}$ (Anderson et al., 2000; Jones et al., 2011). In addition to the gas species, aerosol extinction coefficient profiles for the upper troposphere through the stratosphere are reported at four wavelengths $(2.45,3.40,3.46$, and $5.26 \mu \mathrm{m})$. Broadly, these data show the immediate aftermath of the June 1991 Pinatubo eruption and the long recovery of stratospheric aerosol levels throughout the 1990s. This is followed by a relatively low aerosol loading period between 2000 and the end of the mission where only a few minor volcanic events disturb an otherwise quiescent stratosphere.

HALOE aerosol extinction coefficient profiles are derived as a residual from the gas species retrievals at each wavelength using a methodology that is described in Hervig et al. (1993) with some additional detail reported in Hervig et al. (1996). The aerosol extinction coefficient data is corrected for the gas species measured at those wavelengths as denoted in Table 2. In addition, the contributions by species which absorb at the aerosol channel wavelength (but are not the target measurement) are also removed from the residual extinction particularly if they are measured by HALOE at another wavelength. This is also denoted in Table 1. One important exception is that $\mathrm{NO}_{2}$ absorption is not removed from the aerosol extinction coefficient measurement at $3.40 \mu \mathrm{m}$ (E. Remsberg, personal communication, 2012). As will be demonstrated below, this leaves an artifact in the aerosol extinction coefficient values at this wavelength that is noteworthy after 1995. Some species that are not directly measured by HALOE (or not measured at all relevant altitudes) are removed from the residual extinction using climatological values for the interfering species. The climatologies used in this process were constructed as a part of the Upper Atmosphere Pilot Database (UAPD). HALOE makes use of $\mathrm{N}_{2} \mathrm{O}$ and $\mathrm{CH}_{4}$ (from near the tropopause and below) from this dataset which are based on data from the Stratospheric and Mesospheric 

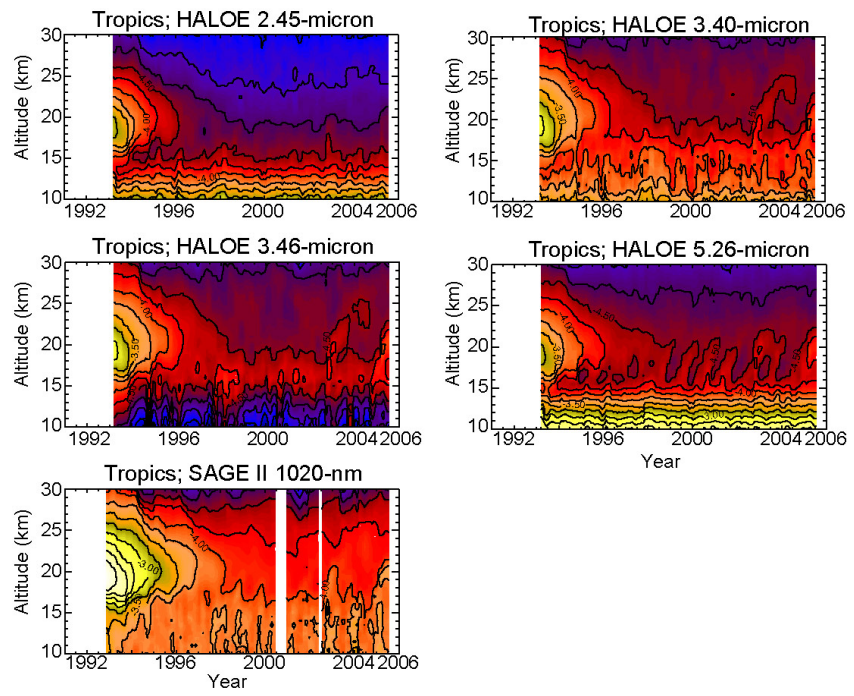

Fig. 2. This figure shows the 3-month running median of aerosol extinction coefficient between $10^{\circ} \mathrm{S}$ and $10^{\circ} \mathrm{N}$ for the 4 HALOE channels and the SAGE II 1020-nm measurements.

Sounder (SAMS) mission in 1979 and balloon-based profiles (Jackman et al., 1989; Jones and Pyle, 1984).

Many climatologies of SAD have been derived from SAGE II and HALOE independently (Thomason et al., 1997; Steele and Turco, 1997; Wang et al., 1989; Yue, 1999; Hervig et al., 1998). The goal of this paper is to evaluate the HALOE aerosol extinction coefficient data as the first necessary step in a process that will eventually allow the production of a combined HALOE/SAGE II aerosol climatology of derived aerosol products including surface area density (SAD) and a mechanism to produce complete aerosol extinction/absorption spectra suitable for use in climate modeling. There are only very limited directly comparable measurements to HALOE aerosol extinction coefficient measurements (e.g., Cryogenic Limb Array Etalon Spectrometer (CLAES) through May 1993). As a result, past evaluations of HALOE aerosol extinction coefficient measurements have been focused on the strongly volcanic periods prior to 1995 and measurements from optical particle counters (e.g., Hervig et al., 1996) or dependent on using HALOE-derived aerosol size distributions to produce comparable bulk properties like SAD or extinction at other visible wavelengths (e.g., Hervig and Deshler, 2002). Herein, I attempt to evaluate each HALOE aerosol channel with as little dependence on assumptions regarding the underlying size distribution as possible. I do not consider the HALOE aerosol size distribution parameters or bulk parameters derived from those values since they are not relevant to the final goal of this study. In any case, the HALOE size distribution fits reported in the official data files are based on multiple HALOE aerosol extinction coefficient values and thus may mask or exacerbate issues at individual wavelengths.
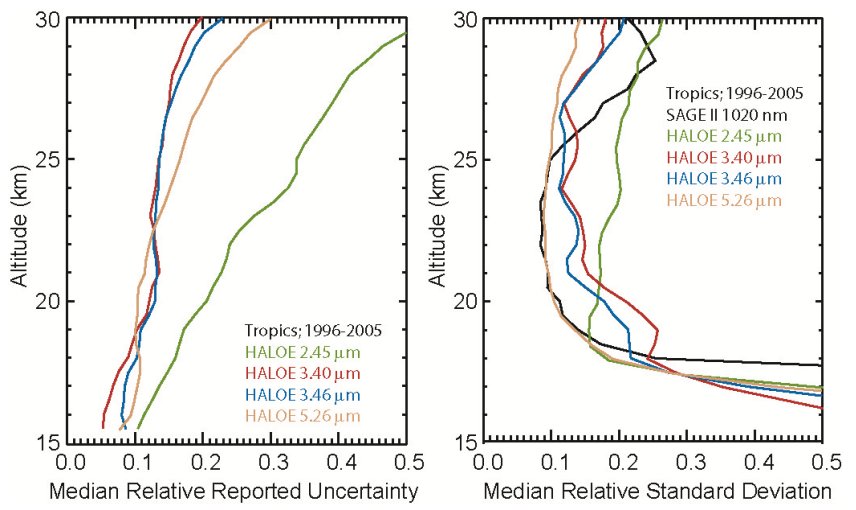

Fig. 3. This figure shows the median relative uncertainty in the four HALOE aerosol extinction channels between $10^{\circ} \mathrm{S}$ and $10^{\circ} \mathrm{N}$ and 1996 and 2005 (left) and the median relative standard based on a 3-month running (similar to the analysis shown in Fig. 2) in the four HALOE aerosol extinction channels and the SAGE II 1020$\mathrm{nm}$ aerosol extinction channel between $10^{\circ} \mathrm{S}$ and $10^{\circ} \mathrm{N}$ and 1996 and 2005 (right).

\section{General morphology of the HALOE aerosol observations}

Figure 2 shows 3-month running median depictions of aerosol extinction coefficient at 2.45 (a), 3.40 (b), 3.46 (c), and $5.26 \mu \mathrm{m}(\mathrm{d})$ for $10^{\circ} \mathrm{S}$ to $10^{\circ} \mathrm{N}$ in units of $1 \mathrm{~km}^{-1}$. Note that, while the bulk of the following analysis focuses on the tropics, the conclusions HALOE aerosol extinction coefficient data quality are independent of latitude. In this case, I have interpolated the HALOE extinction to a $0.5-\mathrm{km}$ grid that matches the SAGE II measurement altitudes. Medians are used as a crude cloud filter; the median-based results of the analysis are essentially identical to mean-based results above $18 \mathrm{~km}$ (where clouds are very rare) and are only modestly affected by cloud presence well into the troposphere. I have also included the SAGE II 1020-nm aerosol extinction coefficient analysis analyzed in an identical manner though a more formal cloud identification scheme for SAGE II is available (Kent et al., 1993). Figure 3 shows a comparison of the reported relative measurement uncertainty (Fig. 3a) and the relative observed variability (Fig. 3b) for tropical measurements for $\left(10^{\circ} \mathrm{S}\right.$ to $\left.10^{\circ} \mathrm{N}\right)$ at each of the four HALOE aerosol extinction coefficient measurement channels for the period 1996 through 2005 where aerosol levels are relatively stable. In this case, I show the median value for each parameter coming from the 3-month depictions shown in Fig. 2. In the tropics, low zonal variability is expected during quiescent periods and often observed for a wide collection of stratospheric components, particularly above $20 \mathrm{~km}$. As a result, the observed variability in this region can be used as a rough stand-in for measurement noise or at least an upper bound on these values (e.g., Cunnold et al., 1984). For the $3.40,3.46$ and $5.26 \mu \mathrm{m}$ channels, the median reported 
measurement uncertainty slowly increases from about $10 \%$ at $20 \mathrm{~km}$ to $20-30 \%$ at $30 \mathrm{~km}$. The observed relative variability in these channels stays roughly in the 10 to $20 \%$ range through the 20 to $30 \mathrm{~km}$ range or comparable to or slightly larger than the reported uncertainties. As a result, it appears that the reported measurement uncertainties for these channels are reasonable estimates of the precision of these measurements. On the other hand, the reported uncertainty for the $2.45 \mu \mathrm{m}$ channel varies from about $20 \%$ at $20 \mathrm{~km}$ to over $50 \%$ at $30 \mathrm{~km}$ whereas the observed variability runs from $15 \%$ at $20 \mathrm{~km}$ to $25 \%$ at $30 \mathrm{~km}$. This difference suggests that the reported uncertainties overestimate the random component of the error budget (precision) for this channel by about a factor of 2.

While there are significant differences in the aerosol extinction kernel (Fig. 1) among the $1020 \mathrm{~nm}, 2.45 \mu \mathrm{m}$, and the longer wavelength HALOE measurement wavelengths (where the kernels are essentially parallel to each other), grossly similar behavior in all five analyses should be observed. In fact, this is broadly what is shown in Fig. 2 (where contours are given in $\log _{10}$ of extinction). There is an intense aerosol layer, centered near $20 \mathrm{~km}$ associated with the 1991 Pinatubo eruption that slowly relaxes toward non-volcanic levels by the late 1990s and the aerosol extinction coefficient at all wavelengths is fairly stable thereafter. Despite the known $\mathrm{NO}_{2}$ contaminant issue, the $3.40 \mu \mathrm{m}$ HALOE channel is qualitatively very similar to the SAGE II 1020-nm channel with a similar structure and duration for the Pinatubo aerosol layer, similar seasonal structure in the clean period and evidence for the impact of two minor eruptions in the $2000 \mathrm{~s}$ (Ruang in 2002 and Manam in 2005). The $3.40 \mu \mathrm{m}$ data does suggest a more rapid increase in aerosol extinction with decreasing altitude in the upper troposphere (below $\sim 17 \mathrm{~km}$ ) than does SAGE II. This may reflect the $\mathrm{NO}_{2}$ contamination or another issue. Since clouds typically exhibit extinction coefficients that are many times larger than aerosol, mixed views of cloud and aerosol often take on the characteristics of cloud events even when the relative fraction of the field of view occupied by cloud is relatively small. As a result, the more rapid increase in extinction coefficient in at $3.40 \mu \mathrm{m}$ relative to the SAGE II $1020 \mathrm{~nm}$ channel may also reflect an increased spreading of "cloud" observations to higher altitudes given the larger field of view for HALOE $(1.6 \mathrm{~km})$ relative to SAGE II (0.5 km) (e.g., Kent et al., 1997). As shown in Fig. 3, SAGE II extinction coefficient relative standard deviation increases more rapidly below $18 \mathrm{~km}$ than do HALOE values. This is also consistent with a FOV differences between two instruments as relatively infrequent SAGE II cloud observations between 16 and $18 \mathrm{~km}$ have a strong impact on the observed standard deviation but virtually no impact on the median extinction coefficient itself.

The $3.46 \mu \mathrm{m}$ channel is very similar to the $1020 \mathrm{~nm}$ SAGE II channel and the $3.40 \mu \mathrm{m}$ channel and shows a similar Pinatubo layer, seasonality in the clear period, and both minor volcanic events. In fact, based on the similarity of their
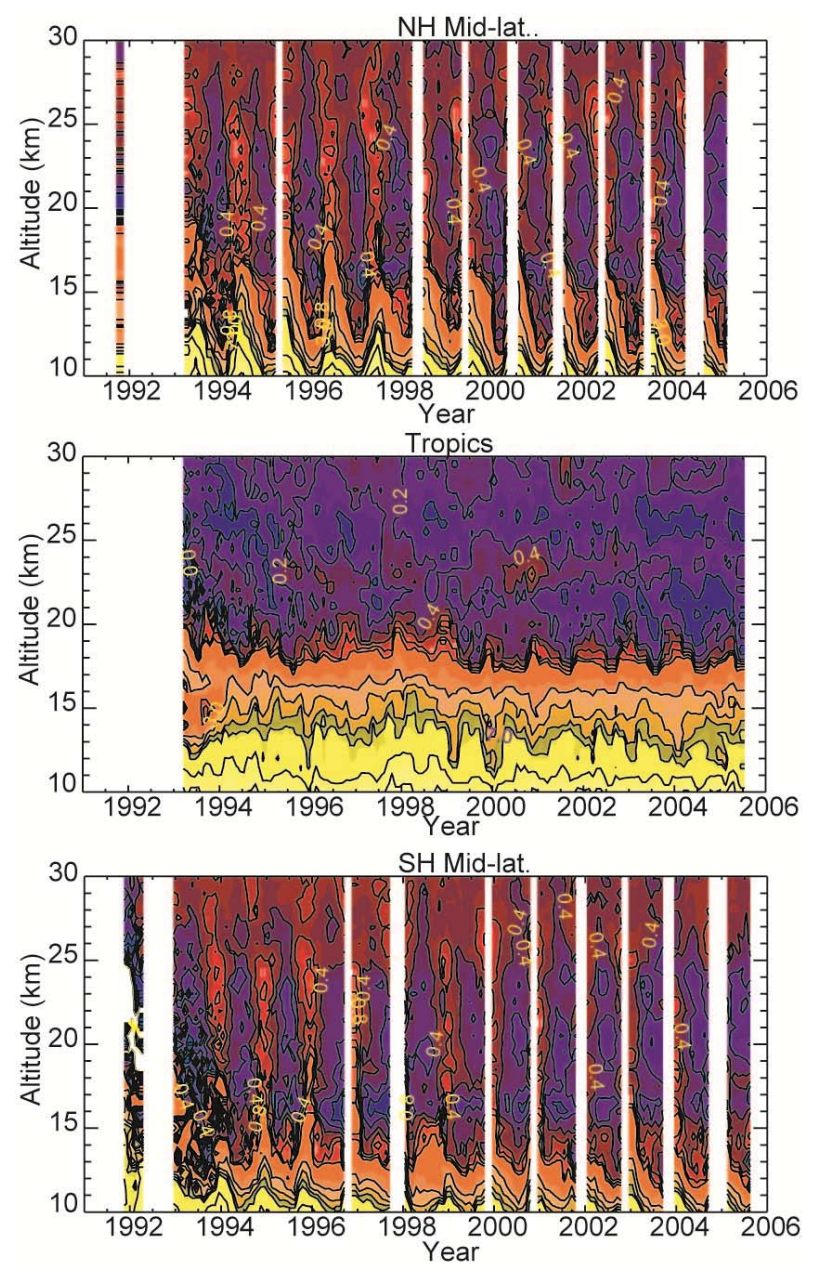

Fig. 4. Median difference between HALOE aerosol extinction coefficient at 3.40 and $3.46 \mu \mathrm{m}$ scaled by a factor of $10^{5}$ and in units of $\mathrm{km}^{-1}$. Line contours are drawn at $-0.8,-0.6,-0.4,-0.2,0,0.2$, $0.4,0.6,0.8,1.0,3,5,7,9,20,40,60,80,100$ with an extra color contour between each isopleth.

extinction coefficient kernels, the 3.40 and $3.46 \mu \mathrm{m}$ channels should be virtually identical except for the affect of the aforementioned $\mathrm{NO}_{2}$ contamination at $3.40 \mu \mathrm{m}$. However, while Fig. 2 shows that, as expected, aerosol extinction at $3.46 \mu \mathrm{m}$ is somewhat less than at $3.40 \mu \mathrm{m}$ in the stratosphere, the difference become much larger at lower altitudes as $3.46 \mu \mathrm{m}$ aerosol extinction coefficient decreases rapidly with distance below $16 \mathrm{~km}$ falling below $10^{-5} \mathrm{~km}^{-1}$ (and continuing to decrease) by $12 \mathrm{~km}$ (compared to values around $2 \times 10^{-4} \mathrm{~km}^{-1}$ at $3.40 \mu \mathrm{m}$ ). Figure 4 shows the mean difference between the 3.40 and $3.46 \mu \mathrm{m}$ aerosol extinction coefficient data in northern and southern mid-latitudes and in the tropics. In the midlatitude stratosphere, the differences show a fairly strongly annual cycle peaking in the summer and exhibiting a morphology and magnitude that is roughly consistent with the known $\mathrm{NO}_{2}$ contamination at $3.40 \mu \mathrm{m}$. Below $20 \mathrm{~km}$, Fig. 4 shows that the divergence between the 3.40 and $3.46 \mu \mathrm{m}$ 
aerosol extinction coefficient data begins as high as $19 \mathrm{~km}$ in the tropics and as high as $17 \mathrm{~km}$ in mid-latitudes or at or slightly above the tropopause. There is clearly a defect in the $3.46 \mu \mathrm{m}$ data at lower altitudes and the character of the anomaly may suggest the over correction of an interfering gas species (overestimating extinction due to absorption) due to either a biased concentration (most likely a climatology) or spectroscopy for an interfering species in this band. This abrupt transition occurs near the altitude at which methane clearing transitions from HALOE observations (in the stratosphere) to use of the UAPD methane values (in the troposphere). Therefore, UAPD tropospheric methane is a potential source of $3.46 \mu \mathrm{m}$ aerosol extinction coefficient bias.

Aerosol extinction coefficient at 2.45 and $5.26 \mu \mathrm{m}$ show similar behavior in the stratosphere as the channels at 3.40 and $3.46 \mu \mathrm{m}$. An exception to this is that the minor eruptions in the 2000s are not clearly detectable in the $2.45 \mu \mathrm{m}$ data. At lower altitudes, both channels show a strong increase with decreasing altitude below $20 \mathrm{~km}$ that does not conform to what is observed at either $1020 \mathrm{~nm}$ by SAGE II or at $3.40 \mu \mathrm{m}$ by HALOE. It is not likely due to clouds as clouds should influence measurements at all HALOE aerosol wavelengths in a similar manner (at least in terms of how it is manifested as opposed to actual extinction coefficient values). For at least the $5.26 \mu \mathrm{m}$ channel, there a clue as to the source of this anomaly in an annual cycle between 15 and $23 \mathrm{~km}$ whose phase and tilt in time that is very analogous to the water vapor tape recorder (Mote et al., 1996). Taken with the rapid increase at and below the tropopause, the behavior of the $5.26 \mu \mathrm{m}$ channels data suggests a water vapor-based artifact in this channel though the artifact could be derived from another gas species that follows a temporal/spatial pattern similar to water vapor. HALOE's $2.45 \mu \mathrm{m}$ aerosol extinction coefficient data has a similar rapid increase below $15 \mathrm{~km}$ as shown by the $5.26 \mu \mathrm{m}$ channel. However, there is no evidence of a tape recorder like structure in the stratosphere. There is some weak absorption by ozone and $\mathrm{N}_{2} \mathrm{O}$ within the $2.45 \mu \mathrm{m}$ channel filter coverage and it is not clear that either is cleared using measured ozone or UAPD $\mathrm{N}_{2} \mathrm{O}$.

\section{Anomaly analysis}

Quantifying the overall quality of the HALOE aerosol extinction coefficient measurements, particularly in the relatively clean period after 1996, is limited by the lack of directly comparable measurements and has, in the past, been based on the conversion of in situ measurements by the University of Wyoming Optical Particle Counter (OPC) (Hervig et al., 1993) and by conversion of the HALOE measurement themselves into extinction at other wavelengths or other derived products (e.g., SAD) using the size distributions derived using multiple HALOE measurement wavelengths (Hervig et al., 1995, 1998; Hervig and Deshler, 2002). Since the goal of this work is to assess individual HALOE chan- nels at near background levels, derived quantities based on size distribution fits are not well suited to this evaluation. Also, while a single mode log-normal is often used in modeling the stratospheric aerosol size distribution and is a reasonable approximation for observed size distributions, multimode and more complex aerosol size distributions are commonly observed (e.g., SPARC, 2006) and observed aerosol extinction coefficient are often sensitive to the details of the size distribution. While it is not totally possible to eliminate some sort of a priori model for the size distribution, I have attempted to minimize the sensitivity of the following evaluation to those assumptions and make no attempt to infer the underlying size distribution. Instead, I use a family of single mode log-normal size distributions (ranges in the mode radius and width) to roughly carve out the space in which ratios of pairs of different wavelengths of aerosol extinction coefficient should exist. Using ratios eliminates sensitivity to total aerosol number density and the size distribution can be considered a smoothing function for the aerosol extinction kernels. As a result, "ratio space" defined through log-normal functions should be fairly representative of any reasonable stratospheric aerosol size distribution. I define a good match to be whenever the observed ratio pairs lie within or near the model space (within $\sim 20 \%$ of the bounds defined by the models). I do not require good matches from one channel to lie near the equivalent location within the log-normal space (i.e., the same implied log-normal size distribution) in a further attempt to minimize the impact of aerosol size distribution assumptions.

Figure 5 shows the distribution of the 3-month running medians (shown as the symbol "+") for the ratio of a HALOE aerosol extinction coefficients relative to the SAGE II $1020 \mathrm{~nm}$ value versus the SAGE II 525 to $1020-\mathrm{nm}$ aerosol extinction coefficient ratio (derived using the methodology used to produce Fig. 2. Also shown are log-normal models results shown as lines for constant size distribution width at values of 1.2, 1.4, 1.6, and 1.8. The SAGE II 525 to $1020 \mathrm{~nm}$ aerosol extinction coefficient ratio can be more or less translated as time since the record begins in 1991 when aerosol showed a small extinction ratio (implying large aerosol) and which increases ( $\sim$ monotonically) into the 2000s. This figure shows that the early data at this altitude for all four HALOE channels are in fairly good agreement with the SAGE II ratios when the SAGE II ratio is less than 2. This occurs early in the HALOE record when extinction is dominated by the Pinatubo event and are the largest observed during the HALOE mission lifetime. Following that period, the ratios using 3.40 and $3.46 \mu$ m HALOE channels remain within or close to the single mode-lognormal space throughout their records. On the other hand, both the 2.45 and $5.26 \mu \mathrm{m}$ ratios consistently increase to where they lay as much as a factor of 2 (at $5.26 \mu \mathrm{m}$ ) or 3 (at $2.45 \mu \mathrm{m}$ ) outside the area bound by the single-mode lognormal model. While some leeway must be granted for the potential for deficiencies in the SAGE II data and the existence of more complex 

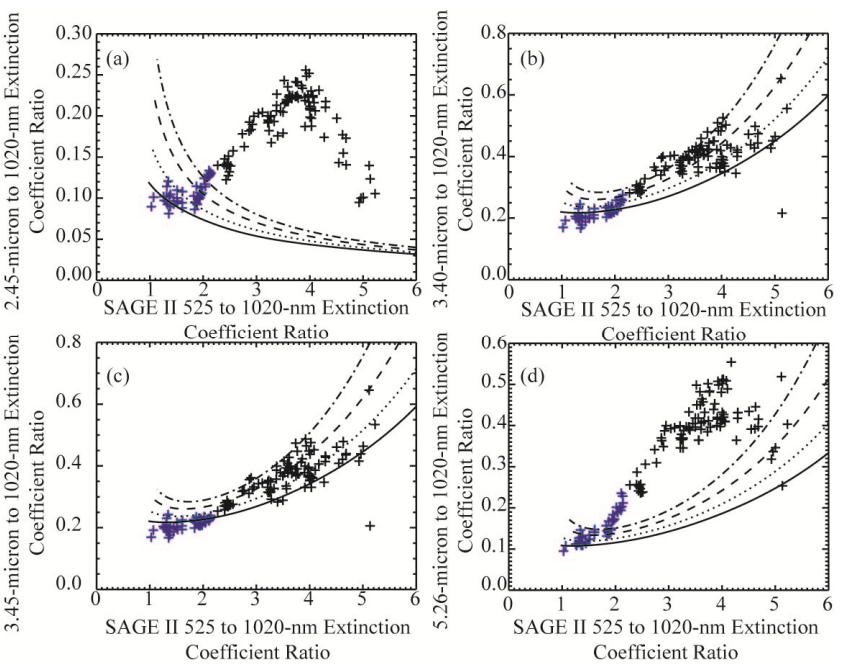

Fig. 5. These figures show the HALOE 2.45 (a), 3.40 (b), 3.46 (c) and $5.26 \mu \mathrm{m}$ (d) to SAGE II 1020-nm aerosol extinction coefficient ratio relative to the SAGE II 525 to $1020-\mathrm{nm}$ aerosol extinction ratio (shown as "+" symbols) computed following the 3-month running medians as shown in Fig. 2 for the Tropics and at $20 \mathrm{~km}$. Data from prior to 1997 is shown in blue. The lines represent model relationships for sulfate aerosol at stratospheric temperatures based on a single mode log-normal with varying mode radius (along the lines) and width (from 1.2 for the solid line to 1.8 for the dash-dot line).

aerosol size distributions, it is virtually impossible to construct any size distribution that would match the observed behavior at 2.45 and $5.26 \mu \mathrm{m}$ relative to SAGE II observations particularly without simultaneously breaking the positive behavior observed at the 3.40 and $3.46 \mu \mathrm{m}$ channels. This figure implies that the 2.45 and $5.26 \mu \mathrm{m}$ HALOE aerosol extinction coefficient measurements are not consistent with the HALOE 3.40 and $3.46 \mu \mathrm{m}$ values as well as the SAGE II measurements.

Selecting the $3.46 \mu \mathrm{m}$ channel as the nominal standard for HALOE aerosol extinction coefficient channels (in much the same way as SAGE II's $1020 \mathrm{~nm}$ channel is treated as the paramount member of the SAGE II ensemble), Fig. 6 shows an analysis similar to that in Fig. 5 using the $3.46 \mu \mathrm{m}$ to $1020 \mathrm{~nm}$ ratio channel as the independent variable relative to ratios of $2.45,3.40$ and $5.26 \mu \mathrm{m}$ relative to $3.46 \mu \mathrm{m}$ as the dependent variable. This reduces the dependence on comparisons to SAGE II measurements particularly for channels at 3.40 and $5.26 \mu \mathrm{m}$ where the model results show virtually no variation with the $3.46 \mu \mathrm{m}$ to $1020 \mathrm{~nm}$ ratio. On the other hand, the 2.45 to $3.46 \mu \mathrm{m}$ extinction coefficient ratio remains sensitive to the use of the SAGE II data since sulfate aerosol is only weakly absorbing at $2.45 \mu \mathrm{m}$ and the resulting extinction kernel (shown in Fig. 1) is a mix of features common to SAGE II aerosol kernels and the longer wavelength HALOE channels where sulfate absorption is very strong. As in the previous figure the $3.46 \mu \mathrm{m}$ to $1020 \mathrm{~nm}$ extinction coefficient ratio is also a rough stand in for increasing
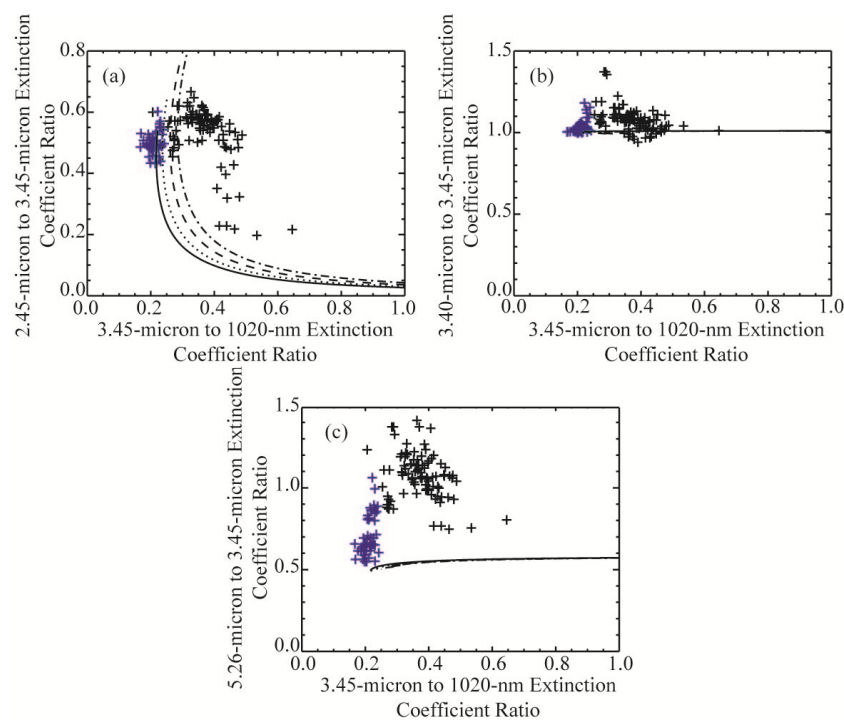

Fig. 6. These figures show the HALOE 2.45 (a), 3.40 (b) and $5.26 \mu \mathrm{m}$ (c) to $3.46 \mu \mathrm{m}$ aerosol extinction ratio relative to the HALOE $3.46 \mu \mathrm{m}$ to SAGE II 1020-nm aerosol extinction ratio (shown as "+" symbols) computed following the 3-month running medians as shown in Fig. 2 for the Tropics and at $20 \mathrm{~km}$. Data from prior to 1997 is shown in blue. The lines represent model relationships for sulfate aerosol at stratospheric temperatures based on a single mode log-normal with varying mode radius (along the lines) and width (from 1.2 for the solid line to 1.8 for the dash-dot line).

time and decreasing absolute extinction coefficient. In Fig. 6, the offset of the $3.40 \mu \mathrm{m}$ channel from its expected relationship with the $3.46 \mu \mathrm{m}$ channel (and virtually independent of the SAGE II 1020-nm extinction coefficient) averages about $+10 \%$ while the 5.26 to $3.46 \mu \mathrm{m}$ (expected to be similarly independent of the $1020 \mathrm{~nm}$ extinction) varies from $+20 \%$ at smallest ratios (i.e., the highest aerosol loading) to more than $100 \%$ at larger ratios. Both of these figures yield interpretations consistent with those drawn from Fig. 5. On the other hand, the 2.45 to $3.46 \mu \mathrm{m}$ figure suggests that the data is more consistent with the $3.46 \mu \mathrm{m}$ and $1020-\mathrm{nm}$ extinction coefficient ratio than would be inferred from the more SAGE II-based comparison shown in Fig. 5 for at least the first half of the data set before substantial departures from the model predictions appear. However, the relationship among the data shows almost no dependence on $3.46 \mu \mathrm{m}$ to $1020 \mathrm{~nm}$ extinction coefficient ratio unlike the strong dependence based on the model results. As with the 5.26- $\mu \mathrm{m}$ channel, results from the $2.45-\mu \mathrm{m}$ channel appear incorrect except at the highest levels of aerosol extinction coefficients observed.

I have computed an aerosol extinction coefficient anomaly as a function of altitude using the single mode log-normal model with a width of 1.6 (the dashed lines in Figs. 5 and 6) for all four HALOE aerosol channels relative to the SAGE II ratios shown in Fig. 5 and for the 2.45, 3.40 and $5.26 \mu \mathrm{m}$ channels relative to the HALOE $3.46 \mu \mathrm{m}$ and 

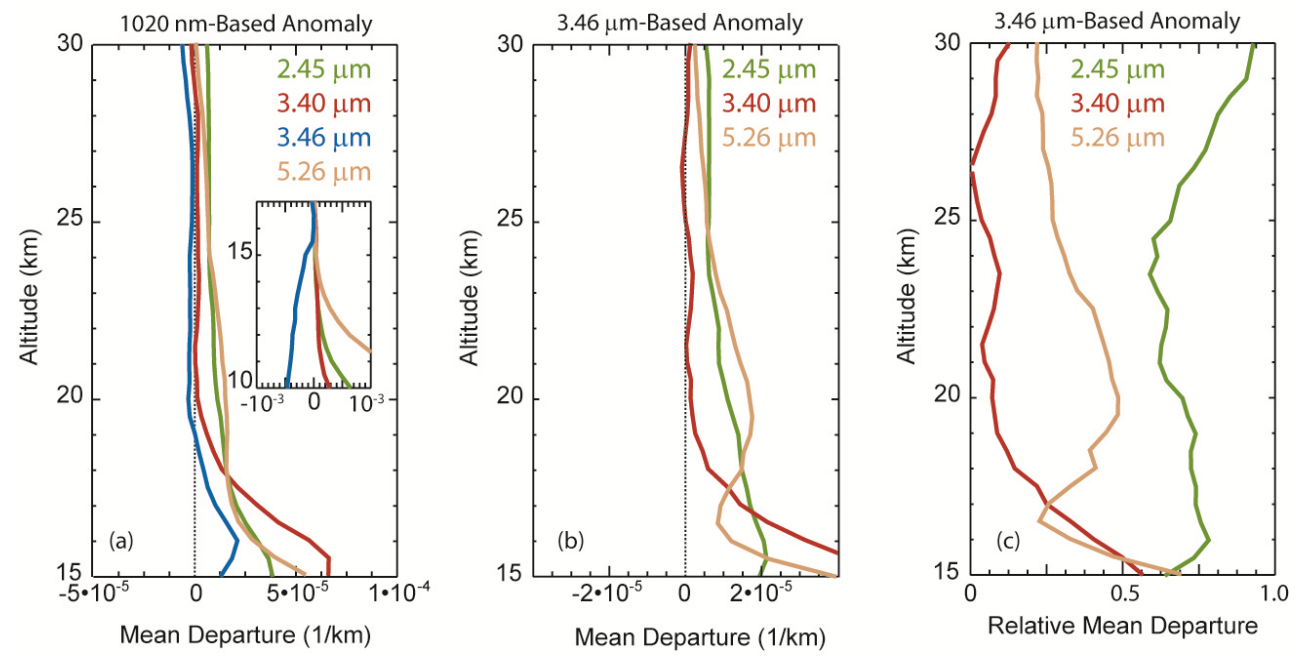

Fig. 7. The figure shows the inferred aerosol extinction coefficient anomalies (the difference between the single mode log-normal size distribution model and the observed channel values) based on the SAGE II 525 to 1020-nm model shown in Fig. 5 for $20 \mathrm{~km}$ (a) and based on the HALOE $3.46 \mu \mathrm{m}$ to SAGE II 1020-nm model (b and c) shown in Fig. 6 for a size distribution width of 1.6. The inset in (a) shows the 1020-nm anomaly below $17 \mathrm{~km}$ with an expanded extinction coefficient scale (in $\mathrm{km}^{-1}$ ).

SAGE II 1020-nm channel ratios shown in Fig. 6. In Fig. 5, the anomaly is computed as the SAGE II 1020-nm extinction coefficient times the difference between the model prediction for the HALOE extinction coefficient values (relative to SAGE II 1020-nm extinction and based on the observed SAGE II 525 to 1020 -nm extinction) and the observed HALOE extinction relative to the SAGE II 1020-nm extinction coefficient. For this analysis I have limited the altitude range to 15 to $30 \mathrm{~km}$ and show the median differences for 1996 through the end of the record and latitudes from $10^{\circ} \mathrm{S}$ to $10^{\circ} \mathrm{N}$. Given the limitations of the anomaly calculation, there is some absolute uncertainty that may vary as a function of time and altitude (as the true underlying size distribution changes) so that the differences shown in Fig. 7 should be considered only estimates of the potential for bias in any of the channels. Also, since I have based this analysis on the $3.46 \mu \mathrm{m}$ channel care must be used in interpreting the analysis below $19 \mathrm{~km}$ where there is obvious degradation in this channels performance. Despite this, I used the $3.46 \mu \mathrm{m}$ channel as the base HALOE extinction measurement because it lacks the known $\mathrm{NO}_{2}$-based bias of the $3.40 \mu \mathrm{m}$ channel throughout the depth of the profile and other channels are far more suspect. Figure 7a shows the anomalies in the all four channels relative to the SAGE II-based predictions and demonstrates a consistent picture between 20 and $30 \mathrm{~km}$ of small anomalies $\left(\sim \pm 10^{-6} \mathrm{~km}^{-1}\right)$ for 3.40 and $3.46 \mu \mathrm{m}$ but significantly larger ones at 2.45 and $5.26 \mu \mathrm{m}\left(\sim 10^{-5} \mathrm{~km}^{-1}\right)$. However, all four channels show much larger deviations from the model predictions below $15 \mathrm{~km}$ (shown in the inset on Fig. 7a) and with values larger than $10^{-3} \mathrm{~km}^{-1}$ at $5.26 \mu \mathrm{m}$. Figure $7 \mathrm{~b}$ and $\mathrm{c}$ shows the anomalies based on the $3.46 \mu \mathrm{m}$ to $1020-\mathrm{nm}$ aerosol extinction ratio in absolute and relative sense. The differences between the 3.40 and $3.46 \mu \mathrm{m}$ extinction coefficients are on the order of $10^{-6} \mathrm{~km}^{-1}$ or about $10 \%$ of the overall measurement between 20 and $30 \mathrm{~km}$. This difference is fairly consistent with the expected $\mathrm{NO}_{2}$ absorption at $3.40 \mu \mathrm{m}$ and suggests that these two channels would be in excellent agreement in this altitude range if the effects of $\mathrm{NO}_{2}$ absorption were removed from the $3.40 \mu \mathrm{m}$ channel. On the other hand, the channels at 2.45 and $5.26 \mu \mathrm{m}$ show differences on the order of 0.5 to $1 \times 10^{-5} \mathrm{~km}^{-1}$ which represent a 20 to $50 \%$ anomaly at $5.26 \mu \mathrm{m}$ and 60 to $95 \%$ at $2.45 \mu \mathrm{m}$. It is possible that more complicated size distributions and more diverse composition (e.g., ice or organics) would account for some of the apparent deficiencies observed herein, however, I believe that the bulk of the problems are HALOE data quality issues.

It is beyond the scope of this paper to fully diagnose and repair deficiencies in HALOE aerosol extinction coefficient data. Nonetheless, given inferences I have already drawn regarding the potential for the residuals to arise from the failure to effectively remove interfering species from the aerosol retrievals, I have made further efforts to identify potential candidates as sources for the observed data quality issues. To do this, I have computed the correlation and its uncertainty between the estimated aerosol extinction coefficient anomalies and the seven gas species reported by HALOE. As in Fig. 7, I have limited the analysis to 15 to $30 \mathrm{~km}$ and for HALOE events from 1996 to the end of the record and latitudes from $10^{\circ} \mathrm{S}$ to $10^{\circ} \mathrm{N}$. It should be kept in mind that correlation between the estimated aerosol anomalies and any gas species may imply a causal relationship between these parameters or a mutual correlation to another, perhaps unmeasured, parameter. Figure 8 shows the correlation of the $3.46 \mu \mathrm{m}$ anomaly 

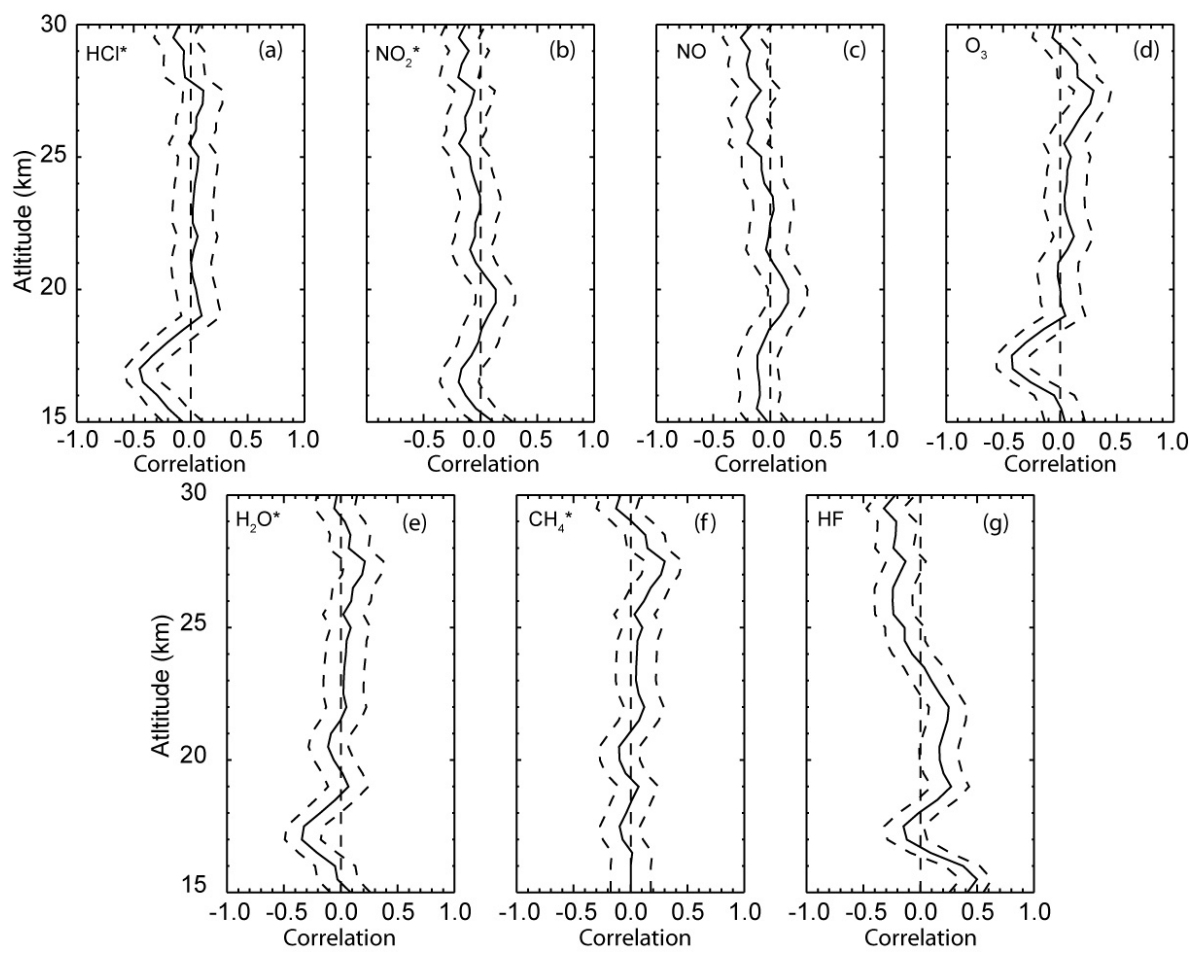

Fig. 8. Correlation of $3.46 \mu \mathrm{m}$ anomalies based on the SAGE II 525/1020 model with HALOE measured species.
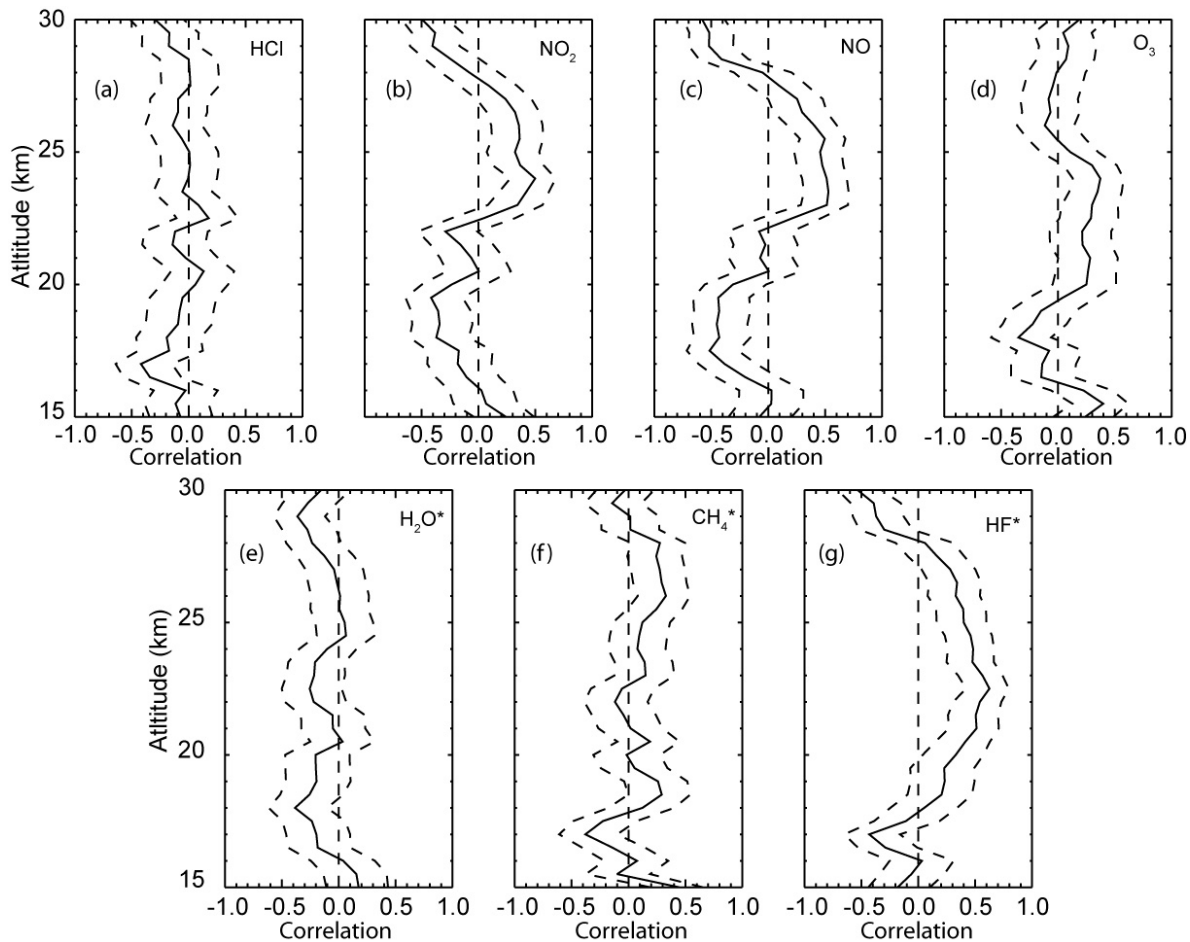

Fig. 9. Correlation of $2.45 \mu \mathrm{m}$ anomalies based on the HALOE $3.46 \mu \mathrm{m}$ model with HALOE measured species. 

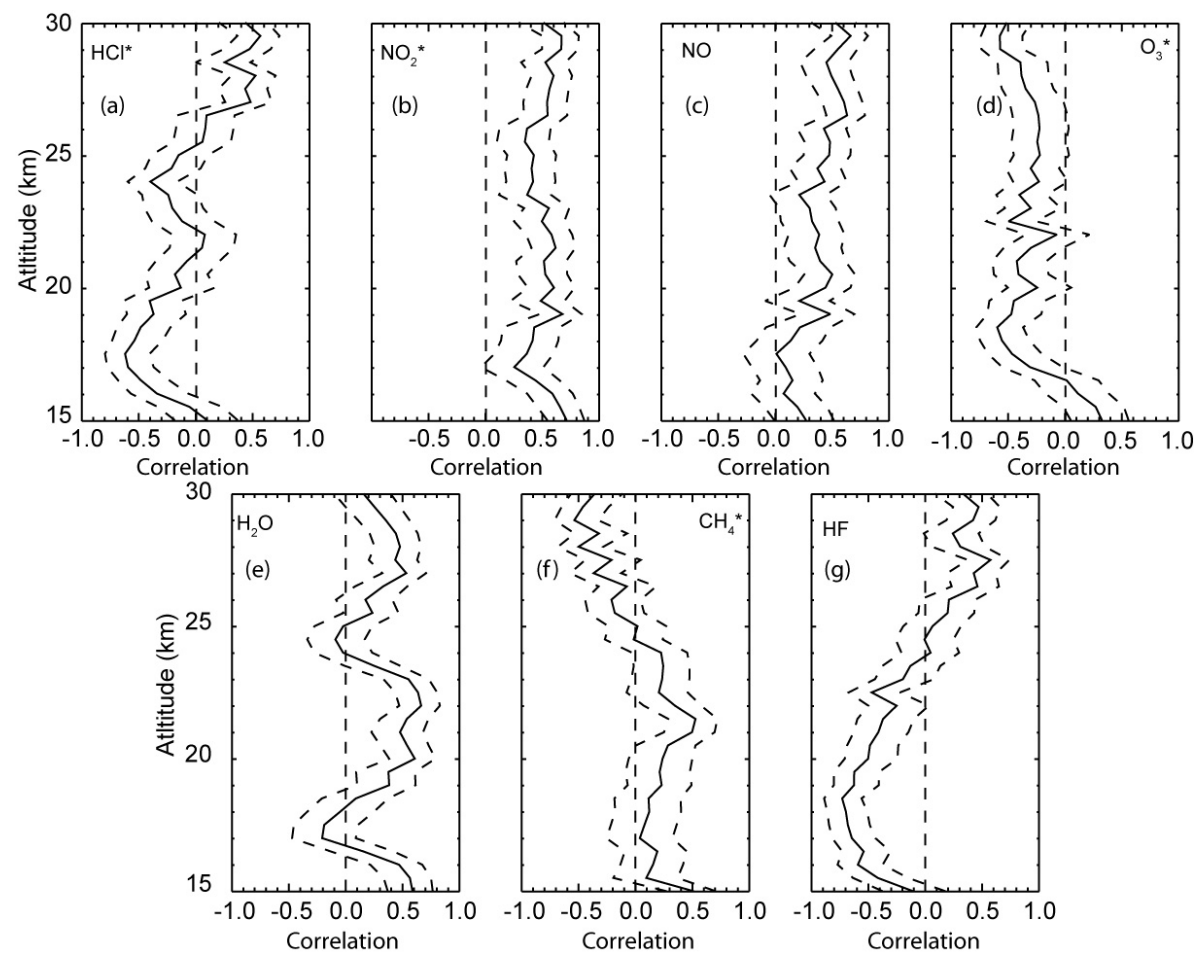

Fig. 10. Correlation of $3.40 \mu \mathrm{m}$ anomalies based on the HALOE $3.46 \mu \mathrm{m}$ model with HALOE measured species.

(computed using the SAGE II ratios as in Fig. 5) and the seven HALOE gas species. In this case, above $20 \mathrm{~km}$, no consistent evidence for correlations between any gas species and the anomaly is observed though some small but significant correlations with ozone, $\mathrm{CH}_{4}$, and $\mathrm{HF}$ can be noted. Below $20 \mathrm{~km}$, some moderate and significant negative correlations with $\mathrm{HCl}$, ozone, and $\mathrm{H}_{2} \mathrm{O}$ are also seen near $17 \mathrm{~km}$ though they have mostly returned to near zero at $15 \mathrm{~km}$ and so it is not clear if they have any relationship to the bias noted in the $3.46 \mu \mathrm{m}$ channel at and below this altitude.

Figure 9 shows the correlation of the $2.45 \mu \mathrm{m}$ anomaly relative to the HALOE gas species measurements. In this case, we see a clear positive correlation between the anomaly and HF, which is measured at $2.45 \mu \mathrm{m}$, between 18 and $28 \mathrm{~km}$ which suggests an incomplete removal of HF from the aerosol residual. In addition, significant correlations are noted with ozone between 20 and $25 \mathrm{~km}$ (where ozone is a maximum), and $\mathrm{NO}$ and $\mathrm{NO}_{2}$ between 23 and 28 and below $20 \mathrm{~km}$ (with a change in sign). Ozone weakly absorbs at this wavelength and is not listed among the species cleared in the retrieval process (Hervig et al., 1996) and so the aerosol anomalies may plausibly be related to the failure to clear this species. On the other hand, $\mathrm{NO}$ and $\mathrm{NO}_{2}$ do not absorb at this wavelength so the significant correlation may be related to another species or some other process that is correlated with $\mathrm{NO}$ and/or $\mathrm{NO}_{2}$. Figure 10 shows the correlation of the $3.46 \mu \mathrm{m}$ anomaly with the HALOE gas species measurements. In this case, $\mathrm{NO}_{2}$ is positively correlated with the aerosol anomaly throughout the 15 to $20 \mathrm{~km}$ range and reinforces the impact of the failure to clear $\mathrm{NO}_{2}$ at this wavelength. NO is similarly correlated but this is most likely due to the correlated between $\mathrm{NO}$ and $\mathrm{NO}_{2}$ themselves. Ozone has a similar correlation, but opposite in sign, which may again be the result of correlation of ozone and $\mathrm{NO}_{2}$ rather than a signature of residual ozone in the aerosol data though that cannot be totally ruled out. Water vapor also shows some significant positive correlations with some fairly complex vertical structure. Since water is removed using HALOE observations, it is not clear why this correlation exists. Finally, there are some surprisingly strong correlations with HF (in particular) and $\mathrm{HCl}$ although neither has appreciable absorption at this wavelength. At this time, I do not fully understand the source of this correlation. Figure 11 shows the correlation of the $5.26 \mu \mathrm{m}$ anomaly with the HALOE gas species measurements. Here, I find strong correlation with water vapor below $23 \mathrm{~km}$ which seems consistent with the observation of a "tape recorder" like feature in the aerosol extinction coefficient data at this wavelength. I also found strong correlations with $\mathrm{HF}, \mathrm{NO}$ and $\mathrm{NO}_{2}$ above $23 \mathrm{~km}$ although none of them absorb at $5.26 \mu \mathrm{m}$. It is possible that the strong correlation with $\mathrm{NO}$ and $\mathrm{NO}_{2}$ is related to either the failure to remove or an ineffective removal of $\mathrm{N}_{2} \mathrm{O}$ which has significant absorption at $5.26 \mu \mathrm{m}$. Like correlations at $2.45 \mu \mathrm{m}$, I do not fully understand the source of the correlations exhibited by this channel. 

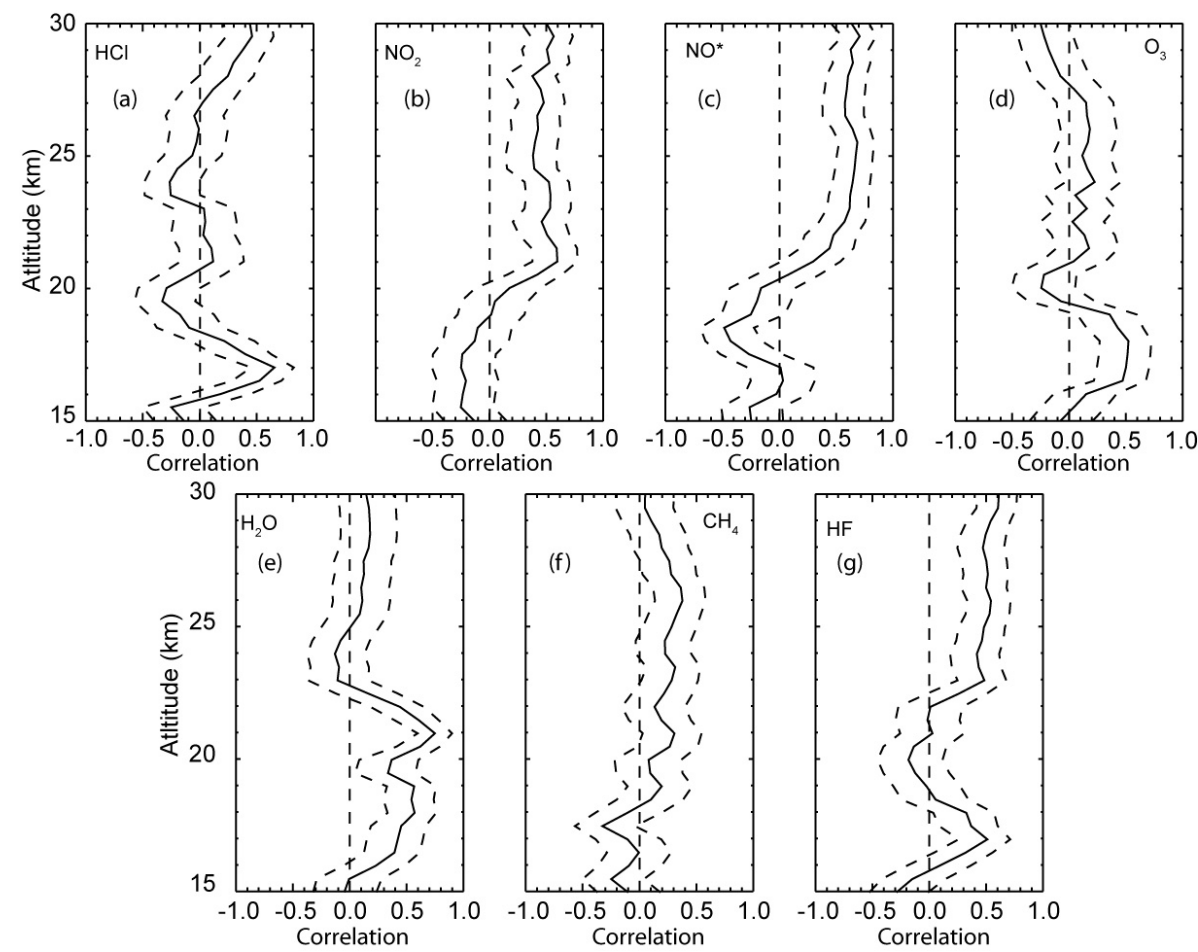

Fig. 11. Correlation of $5.26 \mu \mathrm{m}$ anomalies based on the HALOE $3.46 \mu \mathrm{m}$ model with HALOE measured species.

\section{Application of HALOE data}

The evaluation of HALOE aerosol extinction coefficient data found that one at 3.46- $\mu \mathrm{m}$ channel, is of sufficient quality (without further corrections) to use in an evaluation of aerosol properties $(>19 \mathrm{~km})$. While multiple channels would be preferred, in combination with multiple SAGE II channels, the single channel adds significantly to the information contained in the ensemble and holds the potential to substantially improve estimates of surface area density (SAD) and other bulk properties. Thomason et al. (2008) showed that a notional measurement of aerosol volume substantially reduced the uncertainty inherent in visible wavelength-only measurements as well as modestly increasing the overall estimates for SAD. Following the method used in that paper, I have produced a simple model to combine SAGE II extinction coefficient measurements at 525 and $1020 \mathrm{~nm}$ with those at $3.46 \mu \mathrm{m}$ from HALOE. In this approach, I use the 525 and $1020 \mathrm{~nm}$ extinction coefficient values to estimate a monomodal "large" mode aerosol that reproduces the extinction at both wavelengths exactly. SAD calculated from this mode is the minimum possible SAD that is consistent with those measurements (Thomason et al., 2008). Generally, the radius of this mode is between 0.2 and $0.3 \mu \mathrm{m}$ and the number densities associated with this fit are on the order of $1 \mathrm{~cm}^{-3}$ and much less than the nominal stratospheric value of $\sim 10 \mathrm{~cm}^{-3}$. The extinction at $3.46 \mu \mathrm{m}$ implied by this fit is also much less than observed by HALOE and effectively demonstrates the insensitivity of visible wavelength aerosol extinction to small aerosol $(<0.1 \mu \mathrm{m})$. I then introduce a second monomode which has a number density which brings the total number density to either 5 or $15 \mathrm{~cm}^{-3}$. The size of this mode is selected such that the extinction at $3.46 \mu \mathrm{m}$ is reproduced but do not require either SAGE II extinction to remain fixed. The radii of this mode are usually less than $0.1 \mu \mathrm{m}$. I find the extinction computed using both modes reproduces the $1020 \mathrm{~nm}$ extinction within a few percent of the measured value. The impact at $525 \mathrm{~nm}$ is somewhat larger and is usually between 1 and 2 times the 525-nm measurement uncertainty (10 to $20 \%$ ). The impact at $525 \mathrm{~nm}$ could be reduced with a slightly more sophisticated model. The average of the two fits is used as the "final" SAD product with the profiles based on the 5 and $15 \mathrm{~cm}^{-3}$ representing the lower (from $15 \mathrm{~cm}^{-3}$ ) and upper (from $5 \mathrm{~cm}^{-3}$ ) bounds for SAD. Figure 12 shows the results for the tropics in March 1999 using the method of Thomason et al. (2008) (based SAGE II alone) with an estimated range of close to a factor of 3 throughout the profile. The figure also shows results using the method described above. These results lie within the SAGE II-only result range but generally the mean value is about $30 \%$ higher. Most significantly the range of SAD values is reduced by more than a factor of 3 . Obviously, this model does not (and is not intended to) produce physically realistic aerosol size distributions but is instead intended to produce a viable range for retrieved bulk properties like SAD consistent with observed extinction values but minimally dependent on 


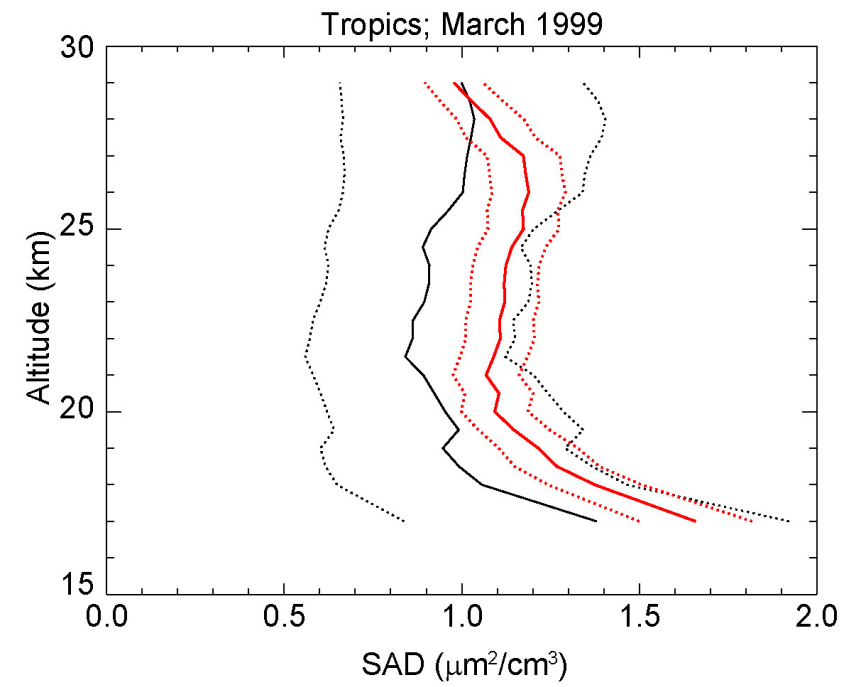

Fig. 12. Comparison of SAD estimates for March 1999 in the tropics $\left(10^{\circ} \mathrm{S}\right.$ to $\left.10^{\circ} \mathrm{N}\right)$ based on SAGE II-only (black) based on the method of Thomason et al. (2008) and using SAGE II 525 and 1020$\mathrm{nm}$ extinction coefficient data along with that from the HALOE $3.46 \mu \mathrm{m}$ based on a modified form of the Thomason et al. (2008) method (red).

assumptions regarding the underlying size distribution. In that regard, this result demonstrates the potential positive impact of employing a mixed visible/infrared aerosol extinction ensemble in the derivation of climate/chemically important aerosol parameters.

\section{Conclusions and recommendations}

In summary, based on the analyses above for the time period after 1996, I have concluded that HALOE's $3.46 \mu \mathrm{m}$ is of good quality above $19 \mathrm{~km}$ and suitable for scientific applications above that altitude. However, I find that it is of increasingly suspect quality at lower altitudes and should not be used below $17 \mathrm{~km}$ under any circumstances. The $3.40 \mu \mathrm{m}$ is biased by about $10 \%$ throughout the stratosphere due to the failure to clear $\mathrm{NO}_{2}$ but otherwise appears to be a high quality product down to $15 \mathrm{~km}$. Its behavior below $15 \mathrm{~km}$ is more cause for concern and should be used with caution. Finally, I find that both the 2.45 and $5.26 \mu \mathrm{m}$ aerosol extinction coefficient measurements are clearly biased and should not be used for scientific applications after the strongest parts of the Pinatubo period. It is clear that the $3.40 \mu \mathrm{m}$ aerosol extinction coefficient measurements can be improved through the inclusion of an $\mathrm{NO}_{2}$ correction and could, in fact, end up as the highest quality overall HALOE aerosol extinction coefficient measurement. This could be done using HALOE's $\mathrm{NO}_{2}$ product in the production of a future version or done using a relatively simple model for $\mathrm{NO}_{2}$ absorption (e.g., MODTRAN) as a post-version correction. On the other hand, fully understanding the deficiencies of the 2.45 and $5.26 \mu \mathrm{m}$ channels probably requires access to the HALOE processing code and supporting data sets and more information regarding these than I have been able to acquire at this time. Nonetheless, careful examination of the UAPD would seem like an important activity. The unique characteristics of the $2.45 \mu \mathrm{m}$ aerosol kernel (size sensitivity with some absorption) make it potentially very valuable in inferring the underlying characteristics of the aerosol size distribution. Improvements to this channel should be considered a high priority. On the other hand, since $5.26 \mu \mathrm{m}$ aerosol extinction coefficient measurements do not offer information that is particularly unique relative to other measurements, future improvements to this channel do not have the same value. Finally, a simple model to demonstrate the power of mixed visible/infrared aerosol extinction coefficient ensembles for the retrieval of bulk aerosol properties demonstrates that a combined HALOE/SAGE II aerosol climatology is feasible and may represent a substantial improvement over independently derived data sets.

Acknowledgements. The author would like to thank the reviewers for helpful comments on this manuscript. In addition, I would like to thank Ellis Remsberg for his comments on suggestions throughout the preparation of this manuscript.

Edited by: M. Dameris

\section{References}

Anderson, J., Russell III, J. M., Solomon, S., and Deaver, L. E.: Halogen Occultation Experiment confirmation of stratospheric chlorine decreases in accordance with the Montreal Protocol, J. Geophys. Res., 105, 4483-4490, 2000.

Cunnold, D. M., Pitts, M. C., and Trepte, C. R.: An intercomparison of SAGE and SBUV ozone observations for March and April 1979, J. Geophys. Res., 89, 5249-5262, 1984.

Hervig, M. E., Russell, J. M., Gordley, L. L., Park, J. H., and Drayson, S. R.: Observations of aerosol by the HALOE experiment onboard UARS: a preliminary validation, Geophys. Res. Lett., 20, 1291-1294, 1993.

Hervig, M. E., Russell, J. M., Gordley, L. L., Daniels, J., Drayson, S. R., and Park, J. H.: Aerosol effects and corrections in the Halogen Occultation Experiment, J. Geophys. Res., 100, 1067-1079, 1995.

Hervig, M. E., Russell, J. M., Gordley, L. L., Park, J. H., Drayson, S. R., and Deshler, T.: Validation of aerosol measurements from the Halogen Occultation Experiment, J. Geophys. Res., 101, 1026710275, 1996.

Hervig, M. E., Deshler, T., and Russell III, J. M.: Aerosol size distributions obtained from HALOE spectral extinction measurements, J. Geophys. Res., 103, 1573-1583, 1998.

Hervig, M. E. and Deshler, T.: Evaluation of aerosol measurements from SAGE II, HALOE, and balloonborne optical particle counters, J.Geophys. Res., 107, 4031-4042, doi:10.1029/2001JD000703, 2002. 
Kent, G. S., Winker, D. M., Osborn, M. T., McCormick, M. P., and Skeens, K. M.: A model for the separation of cloud and aerosol in SAGE II occultation data, J. Geophys. Res., 98, 20725-20735, 1993.

Kent, G. S., Winker, D. M., Vaughan, M. A., Wang, P.-H., and Skeen, K. M.: Simulation of Stratospheric Aerosol and Gas Experiment (SAGE) II cloud measurements using airborne lidar data, J. Geophys. Res., 102, 21795-21807, 1997.

Jackman, C. H., Seals Jr., R. K., and Prather, M. J. (Eds.): TwoDimensional Intercomparison of Stratospheric Models, NASA CP-3042, National Aeronautics and Space Administration, 1989.

Jones, A., Urban, J., Murtagh, D. P., Sanchez, C., Walker, K. A., Livesey, N. J., Froidevaux, L., and Santee, M. L.: Analysis of $\mathrm{HCl}$ and $\mathrm{ClO}$ time series in the upper stratosphere using satellite data sets, Atmos. Chem. Phys., 11, 5321-5333, doi:10.5194/acp11-5321-2011, 2011.

Jones, R. L. and Pyle, J. A.: Observations of $\mathrm{CH}_{4}$ and $\mathrm{N}_{2} \mathrm{O}$ by the NIMBUS 7 SAMS: A comparison with in situ data and twodimensional numerical model calculations, J. Geophys. Res., 89, 5263-5279, 1984.

Mote, P. W., Rosenlof, K. H., McIntyre, M. E., Carr, E. S., Gille, J. C., Holton, J. R., Kinnersley, J. S., Pumphrey, H. C., Russell III, J. M., and Waters, J. W.: An atmospheric tape recorder: The imprint of tropical tropopause temperatures on stratospheric water vapor, J. Geophys. Res., 101, 3989-4006, 1996.
SPARC: Assessment of Stratospheric Aerosol Properties (ASAP), SPARC Report No. 4, WCRP-124, WMO/TD-No. 1295, Feb. 2006, edited by: Thomason, L. and Peter, Th., 2006.

Steele, H. M. and Turco, R. P.: Retrieval of aerosol size distributions from satellite extinction spectra using constrained linear inversion, J. Geophys. Res., 102, 16737-16747, 1997.

Thomason, L. W., Poole, L. R., and Deshler, T. R.: A global climatology of stratospheric aerosol surface area density as deduced from SAGE II: 1984-1994, J. Geophys. Res., 102, 8967-8976, 1997.

Thomason, L. W., Burton, S. P., Luo, B.-P., and Peter, T.: SAGE II measurements of stratospheric aerosol properties at non-volcanic levels, Atmos. Chem. Phys., 8, 983-995, doi:10.5194/acp-8-9832008, 2008.

Wang, P. H., McCormick, M. P., McMaster, L. R., Chu, W. P., Swissler, T. J., Osborn, M. T., Russell, P. B., Oberbeck, V. R., Livingston, J., Rosen, J. M., Hofmann, D. J., Grams, G. W., Fuller, W. H., and Yue, G. K.: SAGE II aerosol data validation based on retrieved aerosol model size distribution from SAGE II aerosol measurements, J. Geophys. Res., 94, 8381-8393, 1989.

Yue, G. K.: A new approach to retrieval of aerosol size distributions and integral properties from SAGE II aerosol extinction spectra, J. Geophys. Res., 104, 27491-27506, 1999. 